\title{
Self-reactive and transplacental-acquired maternal T cells in SCID patients-time to update
}

\author{
Raz Somech*
}

\begin{abstract}
Patients with severe combined immunodeficiency (SCID) typically present with profoundly reduced T cells. In some cases, however, T cells may be affected by defects that allow some T-cell development but compromise T-cell function such as in Omenn syndrome (OS), which is characterized by impaired Tcell differentiation in the presence of abnormal self-reactive cells. One distinctive feature of SCID patients, which can sometimes resemble the clinical picture of OS, is the presence of alloreactive cells that originated from transplacentally acquired maternal T lymphocytes. The traditional view is that self-reactive cells and transplacentally acquired maternal Tcells cannot occur concomitantly in the same OS patient. This review provides an updated functional characterization of transplacentally acquired maternal T cells and compares them with the T cells of an OS patient. An unusual case of an immunodeficient SCID patient with a mild OS phenotype is also presented. This patient had both self-reactive cells and transplacentally acquired maternal $\mathrm{T}$ cells, allowing us to simultaneously evaluate the function and tolerance capacities of both cell types. We propose that coexistence of autologous and maternal Tcells in patients exhibiting mild OS symptoms was rejected because it had not been studied before and not because the cells are mutually exclusive. Moreover, taking into consideration the milder clinical phenotype associated with transplacentally acquired maternal T cells in SCID patients, we believe that these cells may provide some degree of immunity and prevent autoimmunity, even though they do not actually function to protect against infections.
\end{abstract}

Statement of novelty: Autologous and transplacental-acquired maternal T cells can coexist in the same SCID patient. Although both cell types are nonfunctional for protecting against infections, maternal cells provide some degree of immunity and therefore are associated with only mild GVHD symptoms.

\section{Introduction}

Severe combined immunodeficiency (SCID) is the most severe form of inherited primary immunodeficiency. A typical SCID patient is characterized by thymic dysplasia and arrest in $\mathrm{T}$ lymphocyte maturation ( $\mathrm{T}^{-}$SCID phenotype). As a result, the number of $\mathrm{T}$ cells, as determined by fluorescence activated cell sorting (FACS) analysis, is extremely reduced and cell function, as determined by response to mitogenic stimulations, is completely absent (Cooper et al. 2003). SCID patients also display variable expressions of B and NK cells stemming from a specific genetic defect, and are therefore usually categorized into having either SCID with no $\mathrm{T}$ lymphocytes but with B lymphocytes ( $\mathrm{T}^{-} \mathrm{B}^{+} \mathrm{SCID}$ ) or SCID with neither T nor B lymphocytes $\left(\mathrm{T}^{-} \mathrm{B}^{-}\right.$ SCID) (Al-Herz et al. 2014). Regardless of the immunologic phenotype, patients with SCID share similar clinical features, including early-onset severe respiratory tract infections, severe infections with opportunistic pathogens, chronic diarrhea, and failure to thrive. All affected individuals, without exception, will have a fatal
General Pediatric Department B, Immunology Services, Jeffrey Modell Foundation (JMF) Center, Edmond and Lily Safra Children's Hospital, Sheba Medical Center, Tel Hashomer, affiliated to the "Sackler" Faculty of Medicine, Tel Aviv University, Tel Aviv, Israel

*Corresponding author: Raz Somech/raz.somech@sheba.health.gov.il
Submitted 17 September 2014

Accepted 7 October 2014

Available online 28 October 2014

LymphoSign Journal 2:47-52 (2015)

dx.doi.org/10.14785/lpsn-2014-0017 
outcome unless the immune system is promptly restored by means of strict isolation and prophylactic antibiotics, followed by hematopoietic stem cell transplantation or, in some specific cases, gene therapy (Dvorak et al. 2013; Pai et al. 2014). Interestingly, T cells may even be found in normal numbers in some SCID patients (Roifman et al. 2012). Numerous recently identified related defects allow T-cell development on the one hand but compromise $\mathrm{T}$-cell function on the other by affecting proximal or distal steps in intracellular signaling. These functional T-cell immunodeficiencies are characterized by immune dysregulation, autoimmunity, increased risk of malignancies, and infections (Notarangelo, 2014). Some of these forms are due to mutations in the genes that cause SCID or other "leaky" phenotypes due to hypomorphic mutations in SCID-associated genes and some are combined immunodeficiency with residual non-functions cells (Notarangelo 2013). Omenn syndrome (OS) is a typical example of a unique SCID phenotype that is characterized by impaired T-cell differentiation in the presence of abnormal self-reactive cells (Villa et al. 1998). It was first reported in patients with hypomorphic mutations in the recombination activating gene $(R A G) 1$ or $2 \mathrm{~b}$, and it has since been identified in a growing list of other leaky SCIDs as well (Villa et al. 2008). Clinically, OS is characterized by increased susceptibility to severe infections and autoimmune features, including generalized scaly exudative erythroderma, enlarged lymphoid tissues, activation of T-helper type 2 (TH2) lymphocytes, eosinophilia, hyperimmunoglobulin $\mathrm{E}$ ( $\mathrm{IgE}$ ), and peripheral expansion of oligoclonal $\mathrm{T}$ cells. These cells infiltrate specific lymphoid tissues and skin, causing a unique clinical presentation (Aleman et al. 2001). The suggested mechanism underlying this phenomenon is the possible inability of the thymus to delete these abnormal clones, owing to profoundly reduced thymic autoimmune regulator gene (AIRE) mRNA and protein levels that compromise both central and peripheral tolerance mechanisms. Patients with OS were shown to have profound abnormalities of thymic epithelial cell differentiation and severe reduction of thymic dendritic cells, as well as the virtual absence of thymic and peripheral forkhead box P3 $\left(\mathrm{FOXP3}^{+}\right) \mathrm{T}$ regulatory cells (Tregs) (Cavadini et al. 2005; Poliani et al. 2009; Cassani et al. 2010). One distinctive feature of SCID patients, which sometimes can resemble the clinical picture of OS, is the presence of alloreactive cells that had originated from transplacentally acquired maternal $\mathrm{T}$ lymphocytes (Appleton et al. 1994). These cells and the autoreactive cells seen in OS have many clinical and laboratory features in common including atypical skin eruption, hepatosplenomegaly, eosinophilia, elevated IgE levels, the Th2 cytokine pattern, low T-cell activity, and a restricted repertoire of the T-cell receptors (Plebani et al. 1998). The maternal placenta is an incomplete bidirectional barrier that allows the transfer of maternal cells to neonates. Immunocompetent newborns who have effective T-cell immunity can rapidly reject the HLAmismatched maternal cells. In contrast, SCID newborns fail to eliminate these cells, and T-cell engraftment was reported in as many as $40 \%$ of newborns (Müller et al. 2001). Immunologic characterization of these cells and their advantage of passing the placenta and surviving, compared with other maternal $\mathrm{T}$ cells, have not been investigated in depth. The first observation that it was possible to find engraftment of intrauterine-derived maternal T cells in a patient with SCID was reported in 1978 (Pollack et al. 1980). The same authors later reported that 4 out of their 16 SCID patients tested positive to maternal cells. They proved their findings using the E-rosette test to quantify $\mathrm{T}$ cells followed by typed HLA to verify that these cells are maternal (Pollack et al., 1982). These cells were initially considered as being completely nonfunctional, but were later found to have some in vitro $\mathrm{T}$-cell function, with variable proportions of $\mathrm{T}$ cells bearing CD4 and CD8. Moreover, the presence of the Ia antigen and the absence of ecto ${ }^{-} 5^{\prime}-\mathrm{NT}$ activity in these cells were consistent with features of cell activation. This activation is responsible for the clinical phenotype of graft-versus-host disease (GVHD) symptoms observed in some SCID patients (Thompson et al. 1984). Indeed, cutaneous manifestations of maternal engraftment as a result of the GVHD process in patients with SCID are common. They consist of a scaling, erythematous maculopapular eruption spread widely over the trunk and extremities, with nearerythroderma in some patients. Microscopically, the biopsies show parakeratosis, psoriasiform hyperplasia, and spongiosis rash (Denianke et al. 2001). The largest study on engraftment by transplacentally acquired maternal T cells was published in 2001 (Müller et al. 2001). Maternal $\mathrm{T}$ cells were immunologically detected in the circulation in 48 out of a reported 121 SCID patients, with cells ranging from fewer than $100 / 1 \mu \mathrm{L}$ to more than $2000 / 1 \mu \mathrm{L}$. In spite of these cells, however, clinical signs of GVHD were absent in most patients and only one-quarter of them had GVHD manifestations (predominantly involving the skin but also the liver). Patients with prominent skin manifestations of GVHD had mainly activated $\mathrm{CD}^{+} \mathrm{T}$ cells, whereas those with a milder phenotype had mainly nonactivated $\mathrm{CD}^{+}{ }^{+} \mathrm{T}$ cells (Müller et al. 2001). Unusual clinical and immunologic manifestations of transplacentally 
acquired maternal T cells in SCID have been reported; one example shows them causing allograft rejection and immune cytopenias (Palmer et al. 2007). In other rare cases, these cells conferred immunity and protection against infections, enabling SCID patients to reach an older age (Tezcan et al. 2005; Al-Muhsen, 2010). Kobrynski and Abramowsky (2006) reported a rare case of a monoclonal IgA gammopathy occurring in an infant with RAG1 deficiency owing to engraftment of maternal B cells. Touzot et al. (2012) reported a massive expansion of maternal $\mathrm{T}$ cells in response to EpsteinBarr virus infection in a patient with SCID-X-linked. The first report of long-term coexistence of autologous $\mathrm{T}$ cells and high levels of engraftment of haploidentical maternal $\mathrm{T}$ cells was recently published (Cattaneo et al. 2013). In that study, analysis of the autologous cells revealed a naive phenotype with a polyclonal repertoire of proliferating and activated cells in vivo. The residual function and the diversified repertoire of the autologous cells contributed to the excellent clinical status of the reported patient who had no obvious signs suggestive of OS. Similarly, it was speculated by others that the immunosuppressive effect of the maternal cells could modify the clinical symptoms associated with GVHD and cause them to be less severe than the skin manifestations characteristically observed in OS (Vaidya et al. 1991).

A major focus at our lab for the past few years has been the investigation of SCID patients who present with T cells (Amariglio et al. 2010). Our specific objective is to distinguish between the self-reactive cells of OS and the alloreactive cells of transplacentally acquired maternal $\mathrm{T}$ lymphocytes. We have previously shown (Somech et al. 2009) that OS patients have oligoclonal $\mathrm{T}$ cells with limited DNA recombination activity, including the presence of early but not late T-cell maturation events, regardless of the genetic defect underlying the syndrome. Because these cells infiltrate and expand in different organs (e.g., the skin), similar clones can be detected in peripheral blood and the affected organs. Moreover, the clonal expansions in OS patients can respond differently to immunosuppressive therapy; therefore, various treatments to eliminate these clones might be required for different patients (Lev et al. 2012a). We used a TaqMan Low-Density array to show that the transcriptional profile associated with OS features is different from that of normal controls. There were significant changes in $25.5 \%$ of the tested genes, some of which are known to be closely involved with self-tolerance and autoimmunity, specifically with AIRE activity (Somech et al. 2009). To distinguish between self-reactive cells and alloreactive maternally engrafted cells, we compared OS patients with patients with solely maternal cells. Various T-cell functions such as the number of circulating $\mathrm{CD}^{+} \mathrm{T}$ cells, in vitro responses to mitogens, the $\mathrm{T}$-cell receptor (TCR) repertoire, TCR excision circles (TREC) levels, and the number of Tregs were used to investigate the immune status of these patients (Lev et al. 2012b). All patients, regardless of the origin of their cells, exhibited poor T-cell function, reduced thymic activity, and a restricted TCR repertoire together with clonal expansion of certain TCRs. Interestingly, patients with transplacentally acquired maternal $\mathrm{T}$ lymphocytes had less severe clonal expansion and cell restriction in their circulating $\mathrm{CD}^{+}$ cells compared with the "true" Omenn patients. They also had a high fraction of functional circulating Tregs that did not secrete either interferon $\gamma$ or interleukin-2 cytokines following $\mathrm{T}$-cell stimulation, suggesting their ability to suppress autoimmunity. Based on these findings, we suggested that the high-tolerance capacity of the alloreactive transplacentally acquired maternal lymphocytes represents a toleration advantage yet to be associated with severe immunodeficiency. This may explain the milder clinical presentation associated with maternally engrafted cells in SCID patients in contrast with the severe autoimmune manifestations associated with OS. We therefore proposed that some of the immunological parameters that we used can be applied to selected immunodeficient patients who present with residual $\mathrm{T}$ lymphocytes of different origins (see Table 1 in Lev et al. 2012b). However, our study was subject to a major limitation inherent to the assessment of cells from different patients. Therefore, the results could be affected not only by the cell origin of each patient, but also by their different genetic defects, their previous antigen exposure, or their infectious status. Interestingly, the currently accepted view is that self-reactive cells in OS and transplacentally acquired maternal $\mathrm{T}$ cells cannot occur concomitantly in the same patient. This point was emphasized in a recent report that defined the absence of maternal engraftment as one of the OS criteria (Shearer et al. 2014). Indeed, none of 39 OS cases in which transplacentally acquired maternal $\mathrm{T}$ cells were sought was positive for maternal chimerism (Müller et al. 2001). We propose that coexisting autologous and maternal cells in patients exhibiting milder OS symptoms may simply not have been detected and not because they are mutually exclusive. Indeed, we recently had the opportunity to evaluate an unusual case of an immunodeficient SCID patient with mild OS who harbored a novel homozygous mutation in RAG1 (4-BP DEL.1406 TTGC) (Lev et al. 2014). To define the 
patient's circulating T cells, we first studied cell function and thymic activity and found them to be severely reduced. In addition, the repertoire diversity of both TCR-Vb and TCR-Vg was, as expected, restricted and clonal. Meticulous cytogenetic analysis of that patient's cells, however, revealed the concomitant presence of autologous and maternal $\mathrm{T}$ cells, with $38 \%$ of the patient's lymphocytes being of maternal origin and the rest being autologous. That patient's cells could then be distinguished from autologous cells owing to the patient-mother HLA mismatch for HLA-B50 typing. This made it possible for us to study the diversity of TCR-V $\beta$ and the numbers of circulating Tregs $(\mathrm{CD} 4+\mathrm{CD} 25+\mathrm{FOXP} 3+)$ in both cell populations, as well as to compare them with normal values. In line with our proposal, we found that: (i) the patient's autologous TCRs were more clonal and restricted than the maternally engrafted $\mathrm{T}$ cells, and (ii) there were large numbers of circulating Tregs in the maternally engrafted T-cell population, whereas the patient's autologous $\mathrm{T}$ cells had no CD4+CD25+FOXP3+ expression whatsoever (Lev et al. 2014). These findings support our hypothesis that autologous and maternal cells can coexist in SCID patients. Additionally, we believe that maternal cells provide some degree of immunity and prevent autoimmunity, although they still should be considered as nonfunctional for protecting against infections. We therefore consider that co-engraftment of maternal cells could end up being associated with a distinctly milder OS phenotype that could be more prevalent if it were sought. Further functional studies and more widespread reporting of similar patients are needed to confirm our hypothesis that transplacentally acquired maternal $\mathrm{T}$ cells have a tolerance capacity.

\section{Acknowledgements}

The patients with primary immunodeficiencies and their families and the support of the Jeffrey Modell Foundation (JMF) are gratefully acknowledged. Atar Lev, Amos J. Simon, Valentin Nikolenlo, and Ana Rilov are thanked for their hard and diligent work at my lab, and for assisting me in clinical and research activities in the field of primary immunodeficiency.

\section{REFERENCES}

Aleman, K., Noordzij, J.G., De Groot, R., Van Dongen, J.J., and Hartwig, N.G. 2001. Reviewing Omenn syndrome. Eur. J. Pediatric. 160(12):718-725. doi: 10.1007/s004310100816.
Al-Herz, W., Bousfiha, A., Casanova, J.L., Chatila, T., Conley, M.E., Cunningham-Rundles, C., Etzioni, A., Franco, J.L., Gaspar, H.B., Holland, S.M., Klein, C., Nonoyama, S., Ochs, H.D., Oksenhendler, E., Picard, C., Puck, J.M., Sullivan, K., and Tang, M.L.K. 2014. Primary immunodeficiency diseases: an update on the classification from the international union of immunological societies expert committee for primary immunodeficiency. Front. Immunol. 5:162. PMID: 24795713. doi: 10.3389/fimmu.2014.00162.

Al-Muhsen, S.Z. 2010. Delayed presentation of severe combined immunodeficiency due to prolonged maternal T cell engraftment. Ann. Saudi. Med. 30(3): 239-242. PMID: 20427943. doi: 10.4103/0256-4947. 62834.

Amariglio, N., Lev, A., Simon, A., Rosenthal, E., Spirer, Z., Efrati, O., Broides, A., Rechavi, G., and Somech, R. 2010. Molecular assessment of thymus capabilities in the evaluation of T-cell immunodeficiency. Pediatr. Res. 67(2):211-216. PMID: 19858778. doi: 10.1203/ PDR.0b013e3181c6e554.

Appleton, A.L., Curtis, A., Wilkes, J., and Cant, A.J. 1994. Differentiation of materno-fetal GVGD from Omenn's syndrome in pre-BMT patients with severe combined immunodeficiency. Bone Marrow Transpla. 14(1):157-159.

Cassani, B., Poliani, P.L., Moratto, D., Sobacchi, C., Marrella, V., Imperatori, L., Vairo, D., Plebani, A., Giliani, S., Vezzoni, P., Facchetti, F., Porta, F., Notarangelo, L.D., Villa, A., and Badolato, R. 2010. Defect of regulatory $\mathrm{T}$ cells in patients with Omenn syndrome. J. Allergy Clin. Immunol. 125(1):209-216. PMID: 20109747. doi: 10.1016/j.jaci.2009.10.023.

Cattaneo, F., Recher, M., Masneri, S., Baxi, S.N., Fiorini, C., Antonelli, F., Wysocki, C.A., Calderon, J.G., Eibel, H., Smith, A.R., Bonilla, F.A., Tsitsikov, E., Giliani, S., Notarangelo, L.D., and Pai, S.-Y. 2013. Hypomorphic Janus kinase 3 mutations result in a spectrum of immune defects, including partial maternal T-cell engraftment. J. Allergy Clin. Immunol. 131(4):11361145. PMID: 23384681. doi: 10.1016/j.jaci.2012. 12.667.

Cavadini, P., Vermi, W., Facchetti, F., Fontana, S., Nagafuchi, S., Mazzolari, E., Sediva, A., Marrella, V., Villa, A., Fischer, A., Notarangelo, L.D., and Badolato, R. 2005. AIRE deficiency in thymus of 2 patients with Omenn syndrome. J. Clin. Invest. 115(3):728-732. PMID: 15696198. doi: 10.1172/JCI200523087.

Cooper, M.D., Lanier, L.L., Conley, M.E., and Puck, J.M. 2003. Immunodeficiency disorders. Hematology Am. Soc. Hematol. Educ. Program. 2003(1):314-330. doi: 10.1182/asheducation-2003.1.314. 
Denianke, K.S., Frieden, I.J., Cowan, M.J., Williams, M.L., and McCalmont, T.H. 2001. Cutaneous manifestations of maternal engraftment in patients with severe combined immunodeficiency: a clinicopathologic study. Bone Marrow Transplant. 28(3):227-233. PMID: 11535989. doi: 10.1038/sj.bmt.1703128.

Dvorak, C.C., Cowan, M.J., Logan, B.R., Notarangelo, L. D., Griffith, L.M., Puck, J.M., Kohn, D.B., Shearer, W. T., O’Reilly, R.J., Fleisher, T.A., Pai, S.-Y., Hanson, I. C., Pulsipher, M.A., Fuleihan, R., Filipovich, A., Goldman, F., Kapoor, N., Small, T., Smith, A., Chan, K.-W., Cuvelier, G., Heimall, J., Knutsen, A., Loechelt, B., Moore, T., and Buckley, R.H. 2013. The natural history of children with severe combined immunodeficiency: baseline features of the first fifty patients of the primary immune deficiency treatment consortium prospective study 6901. J. Clin. Immunol. 33(7):11561164. PMID: 23818196. doi: 10.1007/s10875-0139917-y.

Kobrynski, L.J., and Abramowsky, C. 2006. Monoclonal IgA gammopathy due to maternal B cells in an infant with severe combined immunodeficiency (SCID) prior to hematopoietic stem cell transplantation. J. Pediatr. Hematol. Oncol. 28(1):53-56. PMID: 16394896.

Lev, A., Simon, A.J., Amariglio, N., Rechavi, G., and Somech, R. 2012a. Selective clinical and immune response of the oligoclonal autoreactive $\mathrm{T}$ cells in Omenn patients after cyclosporin A treatment. Clin. Exp. Immunol. 167(2):338-345. doi: 10.1111/j.13652249.2011.04508.x.

Lev, A., Simon, A.J., Ben-Ari, J., Takagi, D., Stauber, T., Trakhtenbrot, L., Rosenthal, E., Rechavi, G., Amariglio, N., and Somech, R. 2014. Co-existence of clonal expanded autologous and transplacental-acquired maternal $\mathrm{T}$ cells in recombination activating genedeficient severe combined immunodeficiency. Clin. Exp. Immunol. 176(3):380-386. PMID: 24666246. doi: $10.1111 /$ cei.12273.

Lev, A., Simon, A.J., Trakhtenbrot, L., Goldstein, I., Nagar, M., Stepensky, P., Rechavi, G., Amariglio, N., and Somech, R. 2012b. Characterizing T cells in SCID patients presenting with reactive or residual T lymphocytes. Clin. Dev. Immunol. 2012:1-9. doi: 10.1046/j.1365-2249.2000.01359.x.

Müller, S.M., Ege, M., Pottharst, A., Schulz, A.S., Schwarz, K., and Friedrich, W. 2001. Transplacentally acquired maternal $\mathrm{T}$ lymphocytes in severe combined immunodeficiency: a study of 121 patients. Blood. 98:1847-1851. PMID: 11535520.

Notarangelo, L.D. 2013. Partial defects of T-cell development associated with poor T-cell function. J. Allergy
Clin. Immunol. 131(5):1297-1305. PMID: 23465662. doi: 10.1016/j.jaci.2013.01.020.

Notarangelo, L.D. 2014. Combined immunodeficiencies with nonfunctional $\mathrm{T}$ lymphocytes. Adv. Immunol. 121:121-190. PMID: 24388215. doi: 10.1016/B978-012-800100-4.00004-0.

Pai, S.-Y., Logan, B.R., Griffith, L.M., Buckley, R.H., Parrott, R.E., Dvorak, C.C., Kapoor, N., Hanson, I. C., Filipovich, A.H., Jyonouchi, S., Sullivan, K.E., Small, T.N., Burroughs, L., Skoda-Smith, S., Haight, A.E., Grizzle, A., Pulsipher, M.A., Chan, K.W., Fuleihan, R.L., Haddad, E., Loechelt, B., Aquino, V.M., Gillio, A., Davis, J., Knutsen, A., Smith, A.R., Moore, T. B., Schroeder, M.L., Goldman, F.D., Connelly, G.A., Porteus, M.H., Xiang, Q., Shearer, W.T., Fleisher, T. A., Kohn, D.B., Puck, J.M., Notarangelo, L.D., Cowan, M.J., and O'Reilly, R.J. 2014. Transplantation outcomes for severe combined immunodeficiency, 2000-2009. N. Engl. J. Med. 371(5):434-446. PMID: 25075835. doi: 10.1056/NEJMoa1401177.

Palmer, K., Green, T.D., Roberts, J.L., Sajaroff, E., Cooney, M., Parrott, R., Chen, D.F., Reinsmoen, N.L., and Buckley, R.H. 2007. Unusual clinical and immunologic manifestations of transplacentally acquired maternal $\mathrm{T}$ cells in severe combined immunodeficiency. J. Allergy Clin. Immunol. 120(2):423-428. PMID: 17481714. doi: 10.1016/j.jaci.2007.02.047.

Plebani, A., Stringa, M., Prigione, I., Facchetti, P., Ghiotto, F., Airoldi, I., Giacchino, R., Cristina, E., Porta, F., Grossi, C.E., and Pistoia, V. 1998. Engrafted maternal $\mathrm{T}$ cells in human severe combined immunodeficiency: evidence for a $\mathrm{TH} 2$ phenotype and a potential role of apoptosis on the restriction of T-cell receptor variable $\beta$ repertoire. J. Allergy Clin. Immunol. 101(1):131-134. PMID: 9449515. doi: 10.1016/ S0091-6749(98)70207-6.

Poliani, P.L., Facchetti, F., Ravanini, M., Gennery, A.R., Villa, A., Roifman, C.M., and Notarangelo, L.D. 2009. Early defects in human T-cell development severely affect distribution and maturation of thymic stromal cells: possible implications for the pathophysiology of Omenn syndrome. Blood. 114(1):105-108. PMID: 19414857. doi: 10.1182/blood-2009-03-211029. Pollack, M.S., Kapoor, N., Sorell, M., Kim, S.J., Christiansen, F.T., Silver, D.M., Dupont, B., and O'Reilly, R.J. 1980. DR-positive maternal engrafted $T$ cells in a severe combined immunodeficiency patient without graft-versus-host disease. Transplantation. 30(5):331334. PMID: 6450472. doi: 10.1097/00007890-198011 000-00004.

Pollack, M.S., Kirkpatrick, D., Kapoor, N., Dupont, B., and O'Reilly, R.J. 1982. Identification by HLA typing 
of intrauterine-derived maternal $\mathrm{T}$ cells in four patients with severe combined immunodeficiency. N. Engl. J. Med. 307(11):662-666. PMID: 7050708. doi: 10.1056/ NEJM198209093071106.

Roifman, C.M., Somech, R., Kavadas, F., Pires, L., Nahum, A., Dalal, I., and Grunebaum, E. 2012. Defining combined immunodeficiency. J. Allergy Clin. Immunol. 130(1):177-183. PMID: 22664165. doi: 10.1016/j.jaci.2012.04.029.

Shearer, W.T., Dunn, E., Notarangelo, L.D., Dvorak, C. C., Puck, J.M., Logan, B.R., Griffith, L.M., Kohn, D. B., O'Reilly, R.J., Fleisher, T.A., Pai, S.Y., Martinez, C.A., Buckley, R.H., and Cowan, M.J. 2014. Establishing diagnostic criteria for severe combined immunodeficiency disease (SCID), leaky SCID, and Omenn syndrome: the Primary Immune Deficiency Treatment Consortium experience. J. Allergy Clin. Immunol. 133 (4):1092-1098. PMID: 24290292. doi: 10.1016/j.jaci. 2013.09.044.

Somech, R., Simon, A.J., Lev, A., Dalal, I., Spirer, Z., Goldstein, I., Nagar, M., Amariglio, N., Rechavi, G., and Roifman, C.M. 2009. Reduced central tolerance in Omenn syndrome leads to immature self-reactive oligoclonal T cells. J. Allergy Clin. Immunol. 124(4): 793-800. PMID: 19767069. doi: 10.1016/j.jaci.2009. 06.048 .

Tezcan, I., Ersoy, F., Sanal, O., Turul, T., Uckan, D., Balci, S., Hicsonmez, G., Prieur, M., Caillat-Zucmann, S., Le Deist, F., and de Saint Basile, G. 2005. Longterm survival in severe combined immune deficiency: the role of persistent maternal engraftment. J. Pediatr.
146(1):137-140. PMID: 15644840. doi: 10.1016/j. jpeds.2004.09.010.

Thompson, L.F., O'Connor, R.D., and Bastian, J.F. 1984. Phenotype and function of engrafted maternal $\mathrm{T}$ cells in patients with severe combined immunodeficiency. J. Immunol. 133(5):2513-2517. PMID: 6090535. Touzot, F., Dal-Cortivo, L., Verkarre, V., Lim, A., Crucis-Armengaud, A., Moshous, D., Héritier, S., Frange, P., Kaltenbach, S., Blanche, S., Picard, C., Hacein-Bey-Abina, S., Cavazzana-Calvo, M., and Fischer, A. 2012. Massive expansion of maternal T cells in response to EBV infection in a patient with SCID-Xl. Blood. 120(9):1957-1959. PMID: 22936741. doi: 10.1182/blood-2012-04-426833.

Vaidya, S., Mamlok, R., Daeschner, C.W. 3rd, Williams, J., Ruth, J., and Goldblum, R.M. 1991. Suppression of graft-versus-host reaction in severe combined immunodeficiency with maternal-fetal $\mathrm{T}$ cell engraftment. Am. J. Pediatr. Hematol. Oncol. 13(2):172-175. PMID: 2069227. doi: 10.1097/00043426-199122000-00013.

Villa, A., Notarangelo, L.D., and Roifman, C.M. 2008. Omenn syndrome: inflammation in leaky severe combined immunodeficiency. J. Allergy Clin. Immunol. 122(6):1082-1086. PMID: 18992930. doi: 10.1016/j. jaci.2008.09.037.

Villa, A., Santagata, S., Bozzi, F., Giliani, S., Frattini, A., Imberti, L., Gatta, L.B., Ochs, H.D., Schwarz, K., Notarangelo, L.D., Vezzoni, P., and Spanopoulou, E. 1998. Partial V(D)J recombination activity leads to Omenn syndrome. Cell. 93(5):885-896. PMID: 9630231. doi: 10.1016/S0092-8674(00)81448-8. 